\title{
The role of technology for achieving climate policy objectives: overview of the EMF 27 study on global technology and climate policy strategies
}

\author{
Elmar Kriegler • John P. Weyant • Geoffrey J. Blanford • Volker Krey • \\ Leon Clarke • Jae Edmonds • Allen Fawcett • Gunnar Luderer • Keywan Riahi • \\ Richard Richels • Steven K. Rose • Massimo Tavoni • Detlef P. van Vuuren
}

Received: 28 January 2013 / Accepted: 17 September 2013 / Published online: 28 January 2014

(C) Springer Science+Business Media Dordrecht 2014

\begin{abstract}
This article presents the synthesis of results from the Stanford Energy Modeling Forum Study 27, an inter-comparison of 18 energy-economy and integrated assessment models. The study investigated the importance of individual mitigation options such as energy intensity improvements, carbon capture and storage (CCS), nuclear power, solar and wind power and bioenergy for climate mitigation. Limiting the atmospheric greenhouse gas concentration
\end{abstract}

This article is part of the Special Issue on "The EMF27 Study on Global Technology and Climate Policy Strategies" edited by John Weyant, Elmar Kriegler, Geoffrey Blanford, Volker Krey, Jae Edmonds, Keywan Riahi, Richard Richels, and Massimo Tavoni.

Electronic supplementary material The online version of this article (doi:10.1007/s10584-013-0953-7) contains supplementary material, which is available to authorized users.

E. Kriegler $(\bowtie) \cdot$ G. Luderer

Potsdam Institute for Climate Impact Research, Telegrafenberg A31, 14473 Potsdam, Germany

e-mail: kriegler@pik-potsdam.de

J. P. Weyant

Stanford University, Palo Alto, CA, USA

G. J. Blanford $\cdot$ R. Richels $\cdot$ S. K. Rose

Energy and Environmental Analysis Research Group, Electric Power Research Institute, Washington, DC, USA

L. Clarke $\cdot$ J. Edmonds

Pacific Northwest National Laboratory, Joint Global Change Research Institute at the University of Maryland-College Park, College Park, MD, USA

A. Fawcett

U.S. Environmental Protection Agency, Washington, DC, USA

V. Krey $\cdot$ K. Riahi

International Institute for Applied Systems Analysis, Laxenburg, Austria

M. Tavoni

Fondazione Eni Enrico Mattei (FEEM) and Centro-Mediterraneo sui Cambiamenti Climatici (CMCC), Milan, Italy 
to 450 or $550 \mathrm{ppm} \mathrm{CO}_{2}$ equivalent by 2100 would require a decarbonization of the global energy system in the $21^{\text {st }}$ century. Robust characteristics of the energy transformation are increased energy intensity improvements and the electrification of energy end use coupled with a fast decarbonization of the electricity sector. Non-electric energy end use is hardest to decarbonize, particularly in the transport sector. Technology is a key element of climate mitigation. Versatile technologies such as CCS and bioenergy are found to be most important, due in part to their combined ability to produce negative emissions. The importance of individual low-carbon electricity technologies is more limited due to the many alternatives in the sector. The scale of the energy transformation is larger for the $450 \mathrm{ppm}$ than for the $550 \mathrm{ppm}$ $\mathrm{CO}_{2}$ e target. As a result, the achievability and the costs of the $450 \mathrm{ppm}$ target are more sensitive to variations in technology availability.

\section{Introduction}

Anthropogenic climate change is caused by emissions of greenhouse gases (GHGs), aerosols, and other short-lived species from fossil fuel use, industrial processes, agriculture and land use practices. Global GHG emissions have been rising steadily since the industrial revolution and reached $50 \mathrm{GtCO}_{2}$-eq in 2010 (European Commission and Netherlands Environmental Assessment Agency 2011). Mitigating climate change will require a reversal of this trend by reducing and eventually phasing out GHG emissions. Major questions remain as to how and when this transition to a state of zero or very low GHG emissions should be accomplished, how this transition depends on the choice of climate change target, and what is implied for the underlying transition of global energy and land use patterns.

Low-carbon technologies in the energy system have been identified as a key element for mitigating climate change (e.g. Clarke et al. 2008; Edenhofer et al. 2010), but a clear picture about the role of individual mitigation technologies has yet to emerge (Nakicenovic and Nordhaus 2011). The relative importance of mitigation technologies depends not only on their techno-economic characteristics and how they develop in the future, but also on the competition with other energy technologies, the development of future energy demand and the climate policy architecture. Since all of these factors are interconnected and surrounded by large uncertainty, it is important to investigate technology strategies from a system perspective and under a variety of assumptions. The Stanford Energy Modeling (EMF) Study 27 has employed 18 energy-economy and integrated assessment models (EE\&IAMs) from different world regions in a coordinated model comparison exercise to explore the role of various low-carbon technologies in ambitious mitigation scenarios, including different assumptions about technology availability, energy demand and climate policies. The results provide a robust picture of the importance of individual technologies and the determining factors, and constitute a useful resource for climate policy makers.

The EMF27 study builds upon a rich set of model studies on climate mitigation scenarios. Key model comparison studies for instance include the previous EMF climate-change-oriented studies like the EMF19 study on carbon constraints and advanced energy technologies (Weyant 2004), the EMF21 study on non- $\mathrm{CO}_{2}$ Kyoto gas mitigation (Weyant et al. 2006),

D. P. van Vuuren

PBL Netherlands Environmental Assessment Agency, Bilthoven, The Netherlands

D. P. van Vuuren

Department of Geosciences, Utrecht University, Utrecht, The Netherlands 
and the EMF22 study on climate control scenarios including phased participation (Clarke et al. 2009). Other important information comes from recent model intercomparison projects (Edenhofer et al. 2010; Luderer et al. 2012; Calvin et al. 2012) and assessments (Clarke et al. 2008; Krey and Clarke 2011; Riahi et al. 2012) that investigated the role of low-carbon technologies in mitigation scenarios. Compared to these studies, the new contribution of EMF27 is the breadth of technology, energy demand and policy scenarios investigated with a large international consortium, and a detailed exploration of emissions and technology dynamics in individual sectors. Another important new feature of EMF27 is that 14 of the 18 participating EE\&IAMs included the availability of Bio-Energy with Carbon Capture and Storage (BECCS) and - in a few cases - forest and soil carbon stock conservation and/or enhancement. Existing studies have shown that BECCS can be a key option for attaining stringent stabilization targets (Azar et al. 2010; Tavoni and Socolow 2013).

While this paper provides a synthesis of key results, the dimensions of technology availability and climate policy regimes are explored in greater depth in two separate overview papers (Krey et al., Blanford et al. this issue). These are augmented by a set of comparative analyses on Non-Kyoto forcing (Rose et al. (b)), fossil fuel use (McCollum et al.), CCS (Koelbl et al.), renewable energy (Luderer et al.), bioenergy (Rose et al. (a)), land use implications (Popp et al.), nuclear energy (Kim et al.) and energy efficiency (Sugiyama et al.). Individual contributions by EMF27 modeling teams analyze additional topics in further detail.

\section{Methods}

\subsection{Participating models}

Eighteen global energy-economy and integrated assessment models participated in the EMF27 study, originating from the USA (GCAM, FARM, MERGE, Phoenix), Canada (EC-IAM, TIAMWORLD, which is now used globally), the European Union (IMACLIM, IMAGE, MESSAGE, POLES, REMIND, WITCH), Japan (AIM-Enduse, BET, DNE21+, GRAPE), India (GCAMIIM) and the OECD (ENV-Linkages). Further details on these models can be found in the Supplementary Online Material (SOM). The models differ in numerous ways including their sectoral coverage, solution algorithm, representation of GHG emissions, energy demand and supply sectors, baseline assumptions and assumptions about techno-economic parameters. The large ensemble of models permits us to explore ranges of outcomes reflecting both structural as well as parametric uncertainties.

\subsection{Scenario design}

The EMF27 study looked into a large number of technology and policy variations along two key dimensions of mitigation pathways: technology availability and climate policy regime (Table 1).

The technology variations were chosen to reflect generic, but not implausible constraints on the deployment of key mitigation technologies. These include the possibility that CCS will not become commercially available, that nuclear energy is phased out, that the share of intermittent solar and wind power on the electricity grid will be limited, and that modern bioenergy use will be constrained. The study also considered a case with increased energy intensity improvements compared to historical trends included in the baseline. 
Table 1 Scenario design of the EMF27 study

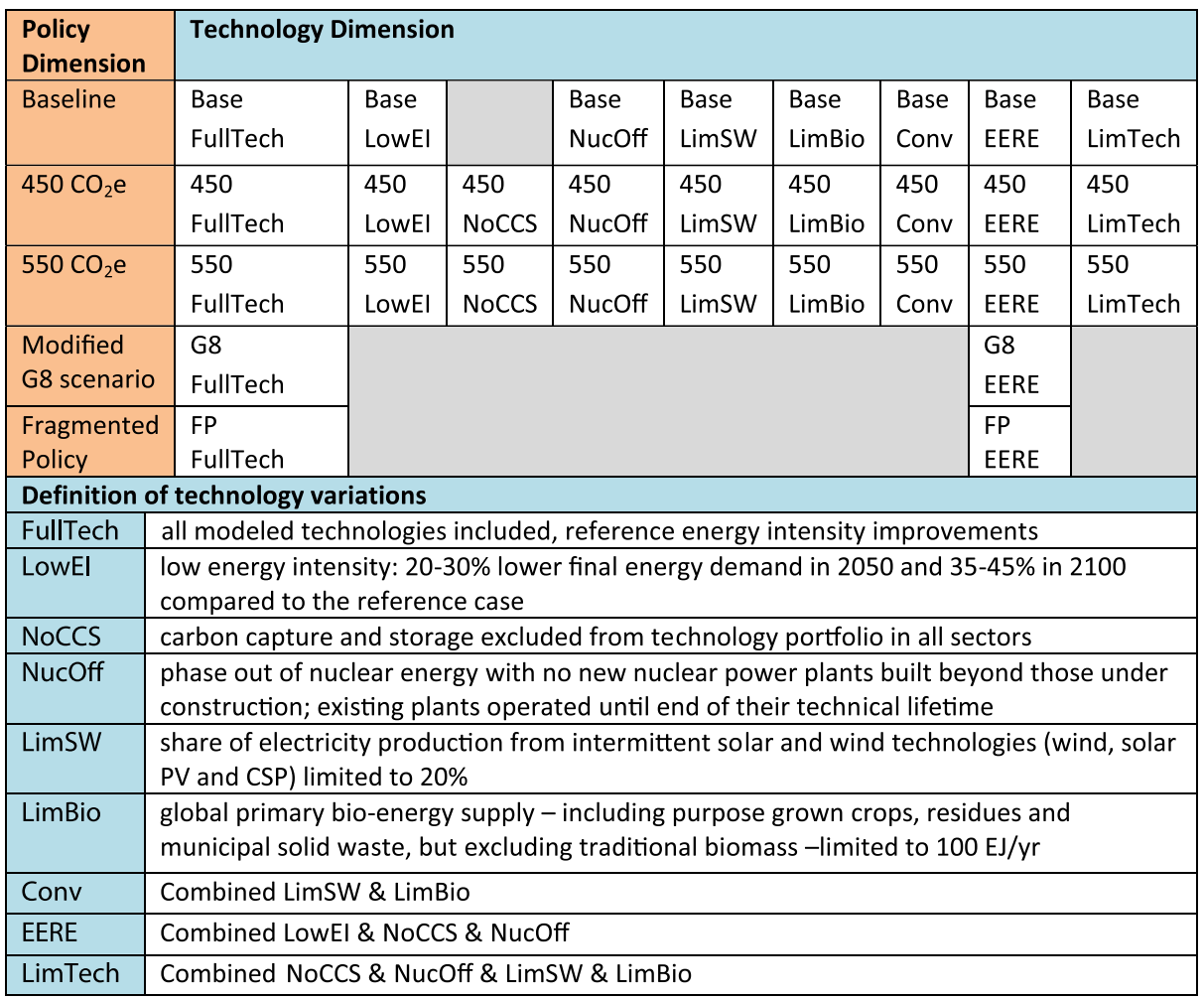

The policy variations included two different target levels of radiative forcing corresponding to atmospheric concentrations of 450 and $550 \mathrm{ppm} \mathrm{CO}_{2}$ equivalent $\left(\mathrm{CO}_{2} \mathrm{e}\right)$ which represent a range of potential long-term goals of international climate policy. The stringency of the lower target is consistent with concurrent interpretations of the goal to keep global mean warming below $2{ }^{\circ} \mathrm{C}$ (Meinshausen et al. 2009). In EMF27, the limit was imposed on the combined radiative forcing from all radiative agents of anthropogenic origin with the exception of nitrate aerosols, mineral dust aerosols, and land use albedo changes (which we call AN3A forcing). The lower 450 limit was set to $2.8 \mathrm{~W} / \mathrm{m}^{2}$ allowing for overshoot before 2100, while the higher 550 limit was set to $3.7 \mathrm{~W} / \mathrm{m}^{2}$ that was not to be exceeded during the $21^{\text {st }}$ century (Blanford et al. this issue).

The models were asked to implement the targets by assuming full when (timing of emission reductions), where (country or region) and what (sector) flexibility of emissions reductions to ensure cost-effective mitigation efforts. In addition, two policy-driven scenarios were implemented that deviated from these idealized assumptions. The first aimed at extrapolating the Copenhagen pledges for individual world regions until 2100 (called fragmented policy scenario - FP - in the following), while the second took up a proposal by the G8 to reduce global emissions by $50 \%$ until 2050, and modified it by assuming a group of non-participating fossil-fuel-rich countries (Blanford et al. this issue). Additional explanation of the study design, the study protocol and the implementation by modeling teams can be found in the SOM. 


\subsection{Target feasibility}

The question of whether or not a target is feasible is important but subject to different interpretations. Furthermore, it cannot be linked directly to whether or not a model returns a solution. For some, a target is feasible if any set of actions exists that could cause the target to be met, whether or not a given model can find such a path. For others, feasibility is purely a model issue that takes into account assumptions about technology availability and how rapidly technology can deploy. For yet others, it is a matter of assessing whether or not the political process could accept a solution, for example carbon prices might be "unacceptably high."

We take the approach that it is most useful to report all available model results, since any supposed technical or economic infeasibility can be assessed best in a comparison across model results (see also Tavoni and Tol 2010). In the remaining cases, where models did not return a solution, and where unrelated numerical problems were not identified as the cause, we took it as an indication that the target is technically or economically infeasible for the given model and scenario setup. Such a finding is, of course, contingent on the model. However, a statistics of how many models did not return a solution among those who attempted the scenario should be indicative of the strain that is imposed on the modeled energy-economy-climate system.

\section{Results}

\subsection{Emissions with and without climate policies}

The EMF27 models project a continued increase of global GHG emissions to 90-136 (Median: 98) $\mathrm{GtCO}_{2} \mathrm{e}$ in 2100 in the absence of climate policy (Fig. 1). Models that calculated the climate response to these baseline emissions show an increase in radiative forcing levels to $6.7-$ $7.4 \mathrm{~W} / \mathrm{m}^{2}$, and global mean temperature to $3.7-4.3^{\circ} \mathrm{C}$ in 2100 compared to preindustrial times ${ }^{1}$ (Figure S1). The assumption of higher energy intensity improvements in the baseline slows the increase of GHG emissions and in some cases stabilizes them to 59-90 (Median: 75) $\mathrm{GtCO}_{2} \mathrm{e}$ in 2100 , but cannot achieve the emissions reductions required by the 450 and 550 ppm $\mathrm{CO}_{2} \mathrm{e}$ targets without climate policy. Likewise, the fragmented policy scenario that attempts to extrapolate the current level of ambition returns GHG emissions to roughly present day levels by $2100\left(39-51 \mathrm{GtCO}_{2} \mathrm{e}\right)$, but does not come close to the stringency of emissions reductions in the 450 and $550 \mathrm{ppm} \mathrm{CO}_{2} \mathrm{e}$ targets (Blanford et al. this issue).

Strong emissions reductions are needed to reach the GHG concentration levels of 450 and $550 \mathrm{ppm} \mathrm{CO}_{2} \mathrm{e}$ in 2100 (Fig. 1). For $550 \mathrm{ppm} \mathrm{CO}_{2} \mathrm{e}, \mathrm{GHG}$ emissions levels are reduced to 26-38 (Median: 32) $\mathrm{GtCO}_{2} \mathrm{e}$ in 2050 and 14-24 (Median: 17) $\mathrm{GtCO}_{2} \mathrm{e}$ in 2100. For 450 ppm $\mathrm{CO}_{2} \mathrm{e}$, emissions reductions are even stronger, leading to 20-28 (Median: 24) $\mathrm{GtCO}_{2}$ emissions in 2050 and close to or below zero emissions ( -9 to $5 \mathrm{GtCO}_{2} \mathrm{e}$ ) by the end of the century. Since overshooting the stabilization target prior to 2100 is allowed in the $450 \mathrm{ppm} \mathrm{CO}_{2} \mathrm{e}$ case but not for $550 \mathrm{ppm} \mathrm{CO}_{2} \mathrm{e}$, emissions trajectories actually remain close to each other in the first half of the century but increasingly diverge in the second half.

In reaching the forcing targets, not only emissions of Kyoto gases, but also other forcing constituents such as aerosols and tropospheric ozone play a role. Rose et al. (this issue (b))

\footnotetext{
${ }^{1}$ Those models used endogenous climate modules that can differ significantly in their response to emissions trajectories, particularly for the climate policy cases. This adds an additional layer of uncertainty to climate outcomes and also affects the amount of residual emissions that models estimate to be consistent with the climate targets.
} 
a

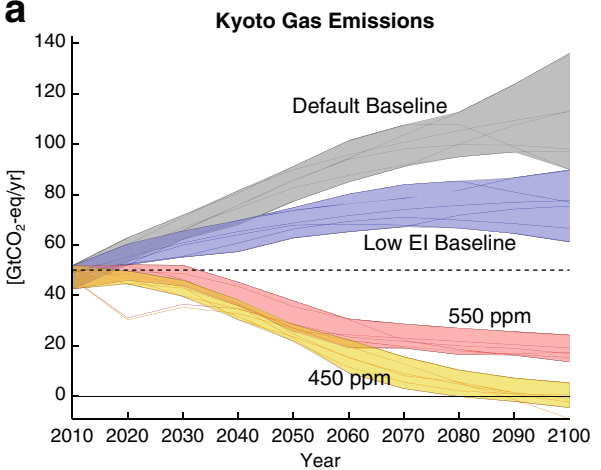

C

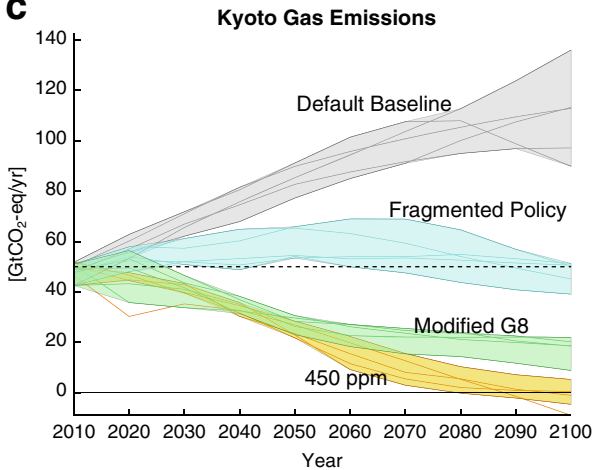

b

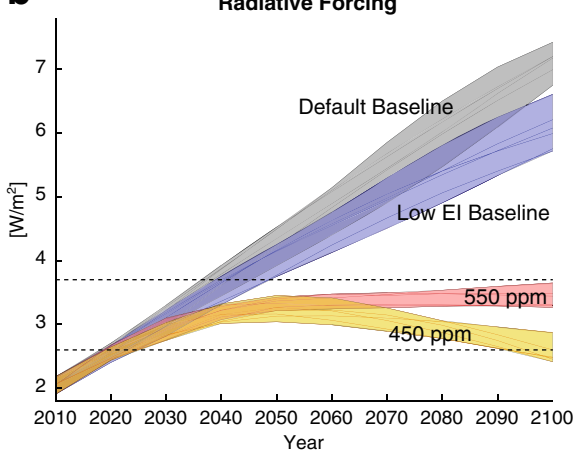

d

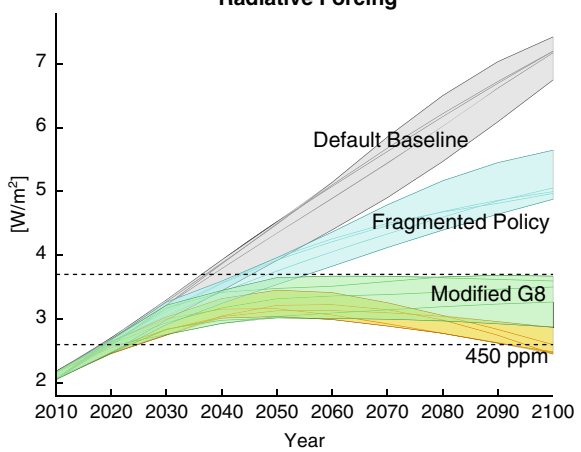

Fig. 1 Kyoto gas emissions (left panels) and total radiative forcing (including albedo, nitrate aerosols and mineral dust; right panels) for two different sets of scenarios in the top and bottom row. All scenarios assume default technology availability. Only the subset of models that calculated all scenarios in a panel out to 2100 was included. (GCAM, IMAGE, MERGE, REMIND, WITCH, MESSAGE; MESSAGE did not run the G8 and FP scenarios, and thus is not included in the lower panels). The 2020 emissions dip in Panels a) and b) is due to large scale afforestation in GCAM in the 450 and $550 \mathrm{ppm} \mathrm{CO}_{2} \mathrm{e}$ pathways

describe and assess the state of current non-Kyoto radiative forcing modeling in a subset of EMF27 models. The study finds aerosol emissions mask significant baseline warming. However, there are large differences across models in projected non-Kyoto emissions and forcing, so further evaluation is merited.

An important finding concerns the breakdown of Kyoto gas abatement efforts into $\mathrm{CO}_{2}$ from fossil fuel combustion and industry (FF\&I), $\mathrm{CO}_{2}$ from land use, and non- $\mathrm{CO}_{2}$ gases (Tables $\mathrm{S} 1, \mathrm{~S} 2$ ). In all models, the scale of $\mathrm{CO}_{2}$ emissions and emissions reductions in the FF\&I sector is much greater than in the other sectors (Blanford et al. this issue; Fig. 2a). Most models indicate that emission reductions are relatively limited in the non- $\mathrm{CO}_{2}$ sectors, which include a variety of sources such as energy, agriculture, industry, and landfills. The land use sector holds the potential for a net increase of the terrestrial carbon sink due to forest and soil carbon enhancement. Only a few models (MESSAGE, GCAM) in EMF27 included this option, and results showed a significant impact on mitigation pathways (Fig. 2b). Models project widely different cumulative $\mathrm{CO}_{2} \mathrm{FF} \& \mathrm{I}$ emissions for the period 2011-2100 ranging from 680 to $1400 \mathrm{GtCO}_{2}$ and $1260-2340 \mathrm{GtCO}_{2}$ for the 450 and $550 \mathrm{ppm} \mathrm{CO}_{2} \mathrm{e}$ targets, respectively (Tables S1, S2). Thus, the models come to different conclusions about what is "required" in any particular sector to meet ambitious climate goals. The breadth of participating models demonstrates a variety of alternative pathways and strategies. 
Figure 2 shows the range of projected land use and fossil fuel and industry $\mathrm{CO}_{2}$ emissions across various sectors. Despite the large model spread, the different scales of the emissions reductions to reach the 450 and $550 \mathrm{ppm}$ climate targets is clearly visible from $2030 \mathrm{on}$. There is also a clear distinction between the profiles of direct emissions from electricity generation and the energy end use sectors (see also Figure S3). The electricity sector is decarbonized first, with close to zero (550) or net negative emissions (450) in 2050, and consistently negative emissions in 2100 for those models that include BECCS. These negative emissions compensate for part of the residual emissions from fossil fuel use in the end use sectors. The transport sector shows the largest residual emissions with emissions levels returning to present day levels by $2030-50$ for $450 \mathrm{ppm}$ $\mathrm{CO}_{2} \mathrm{e}$, and by 2100 for $550 \mathrm{ppm} \mathrm{CO}_{2} \mathrm{e}$.

a

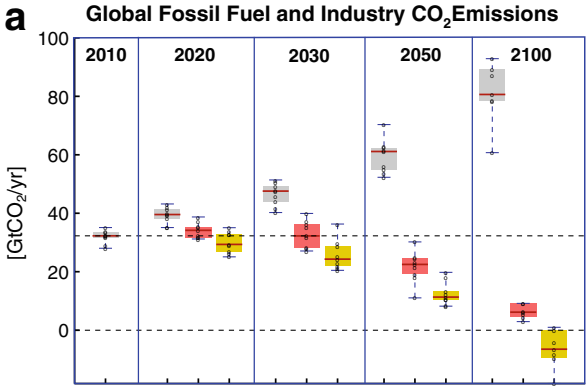

C

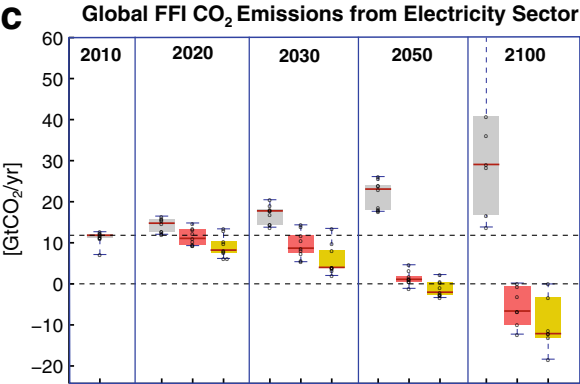

e

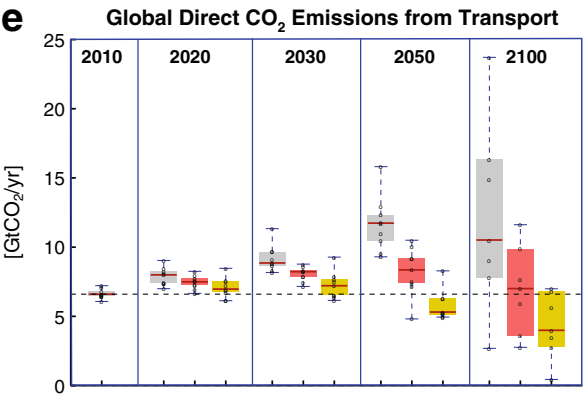

b

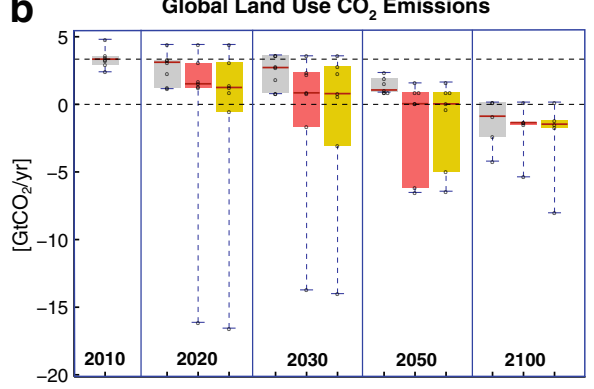

d Global Direct $\mathrm{CO}_{2}$ Emissions, Res \& Comm Sector

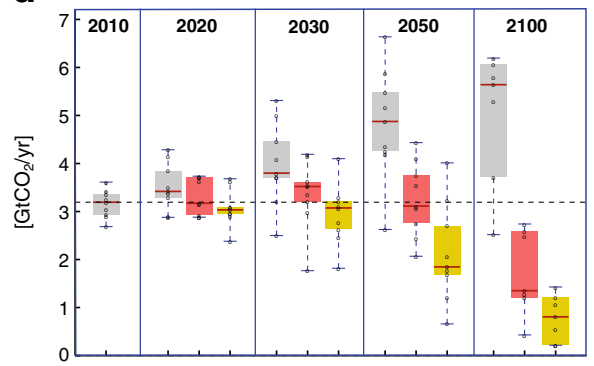

f

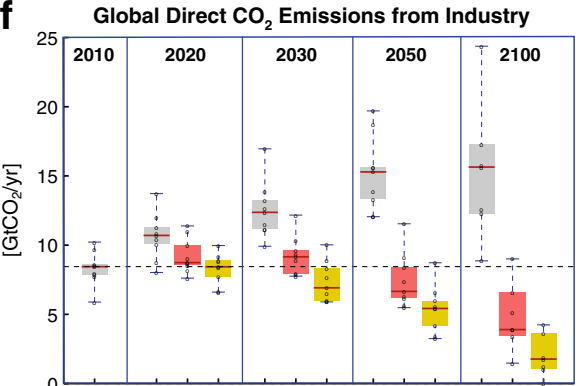

Fig. 2 Range of global direct $\mathrm{CO}_{2}$ emissions from individual sectors (see panel titles). Boxplots show the emissions in the baseline (grey), $550 \mathrm{ppm}$ (red) and $450 \mathrm{ppm} \mathrm{CO}_{2} \mathrm{e}$ (yellow) scenarios assuming default technology availability (FullTech). Boxes highlight the $25^{\text {th }}, 50^{\text {th }}$ (red bar) and $75^{\text {th }}$ percentile of the model sample. The sample includes the 9 models that reported the breakdown of emissions into the electricity and energy end use sectors (AIM-Enduse (until 2050), BET, DNE21+ (until 2050), GCAM, IMACLIM (no landuse $\mathrm{CO}_{2}$ ), IMAGE, MESSAGE, POLES (no landuse $\mathrm{CO}_{2}$ ), TIAM-World) 


\subsection{Economic implications of climate policies}

The economic implications of climate action can be described by various measures. Emissions prices reflect mitigation costs at the margin, i.e. for the next unit of emissions reductions. ${ }^{2}$ The majority of models shows similar price increases for the 450 overshoot and 550 not to exceed targets until 2050, and a stronger increase for $450 \mathrm{ppm} \mathrm{CO}_{2} \mathrm{e}$ in the second half of the century. Figure 3a compares average emissions price levels over the period 2020-2100 at $5 \%$ discounting of future prices. ${ }^{3}$ They range from $\$ 5$ to $\$ 50$ per $\mathrm{tCO}_{2} \mathrm{e}$ for $550 \mathrm{ppm} \mathrm{CO}_{2} \mathrm{e}$ and $\$ 12$ to $\$ 92$ per $\mathrm{tCO}_{2}$ e for 450 ppm $\mathrm{CO}_{2} \mathrm{e}$, and typically increase twofold or more between the two targets. The order of magnitude variation across models is due to differences in model structure and assumptions, particularly those relating to the flexibility of decarbonizing energy use and mitigation requirements for the fossil fuel and industry sector (controlled for on the $\mathrm{x}$ axis). Emissions prices in the fragmented policy scenario vary across regions, and are generally lower than for the stabilization targets, at the expense of achieving significantly lower emissions reductions over the $21^{\text {st }}$ century.

The aggregate macro-economic costs of mitigation are captured to different degrees by different models. Partial equilibrium models report abatement costs for instance as the area under the marginal abatement cost curve (MAC), while general equilibrium models can derive consumption losses including economy wide effects. Such measures (partially) describe the direct costs of mitigation, but neither include climate benefits nor as adverse side effects and co-benefits of climate policy (McCollum et al. 2011; Riahi et al. 2012).

For both climate targets, abatement costs and consumption losses grow faster than the economy in the baseline. Their net present value over the period 2010-2100 (at $5 \%$ discounting) is between $0.4-1.1 \%$ and $0.7-2.2 \%$ (IMACLIM: $8.0 \%$ ), respectively, of the baseline economy for $550 \mathrm{ppm} \mathrm{CO}_{2} \mathrm{e}$, and $0.8-2.9 \%$ and $0.9-3.3 \%$ (IMACLIM: $11.7 \%$ ), respectively, for $450 \mathrm{ppm} \mathrm{CO}_{2} \mathrm{e}$. Costs increase between 25 and $200 \%$ between the two targets (Fig. 3). The large variation across models is due to the factors influencing emissions prices, and the extent to which economy-wide effects and market distortions in the baseline are captured. The IMACLIM model with the most extensive treatment of non-climate market distortions shows the highest costs, which could be reduced by exploiting a potential double dividend of climate policy (Bibas et al. this issue). Cost estimates and their increase between the 550 and $450 \mathrm{CO}_{2} \mathrm{e}$ target can change significantly when technology availability is constrained (see below; Krey et al. this issue).

All cost estimates for the two climate targets hold for the idealized assumption of universal emissions pricing. Models consistently project higher mitigation costs for the G8 policy scenario for similar levels of abatement (Figure S2). This is due to inefficiencies induced by the fact that a group of fossil resource rich countries does not join the global climate regime (Blanford et al. this issue). The low-cost abatement options in these countries are left untouched and there is a limited amount of emissions leakage. Remarkably, the non-participating countries incur significant costs from the adoption of stringent mitigation policies by the rest of the world due to a loss of fossil fuel export revenues.

\footnotetext{
${ }^{2}$ This is true in the context of this study, since no additional climate policy measures such as technology performance standards or subsidies are assumed.

${ }^{3}$ Most of the EMF27 models assume an interest rate of around $5 \%$ per year. The choice of discount rate affects the average price/net present value cost estimates. Lower discount rates lead to higher average prices/net present value costs, if prices/costs increase over time.
} 
A Time-averaged discounted carbon prices over the period 2010-2100
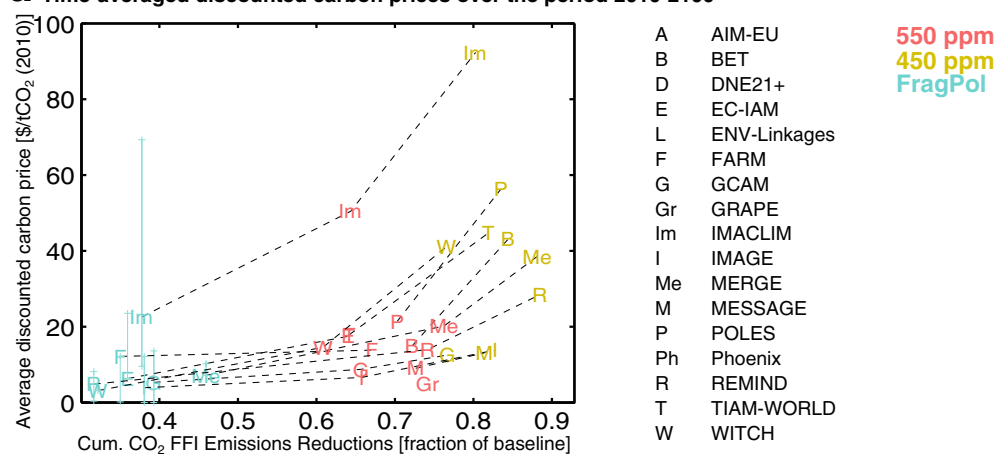

b NPV abatement costs (PE models) 2010-2050
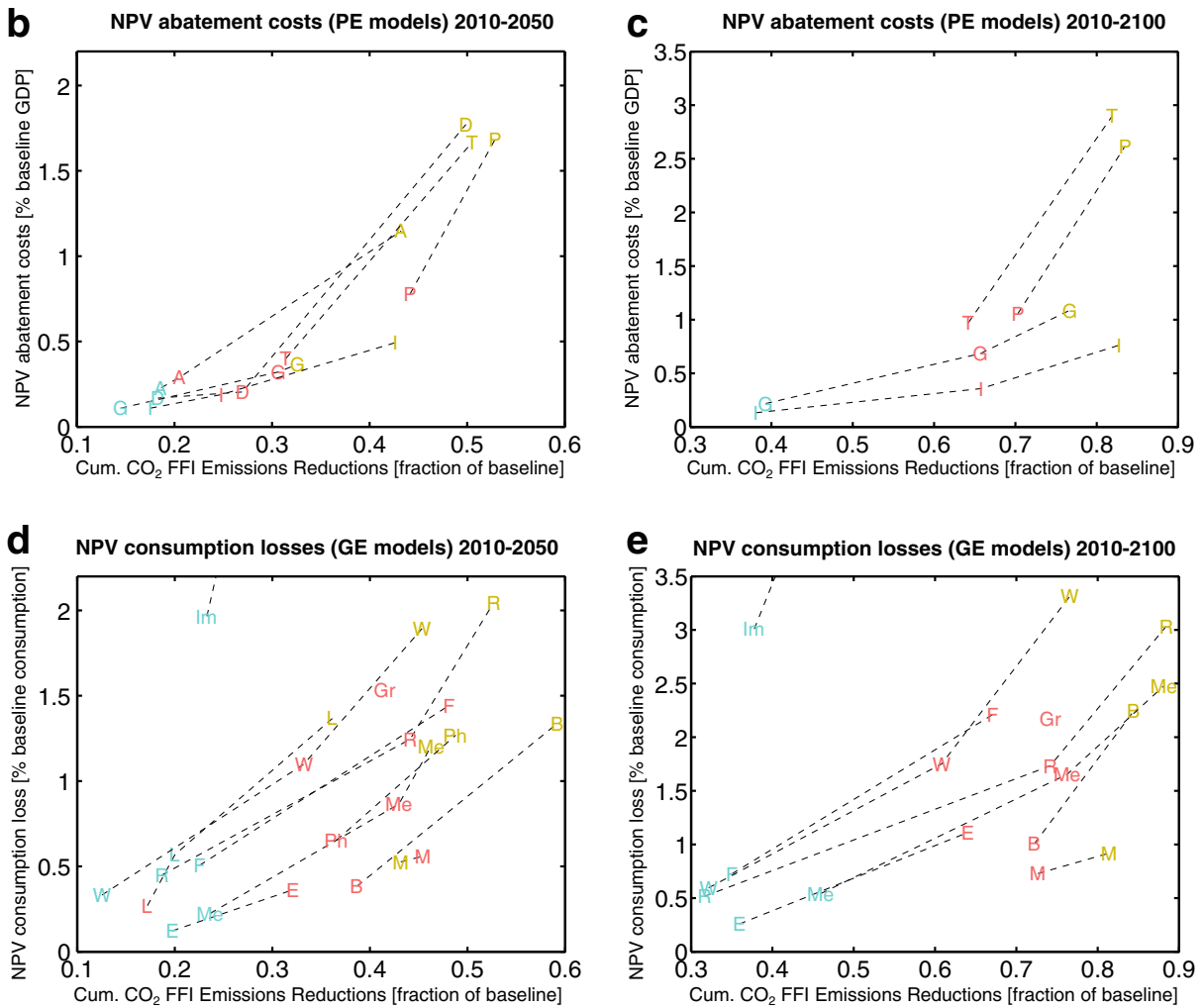

Fig. 3 Global carbon prices discounted at $5 \%$ (averaged over time; Panel a) and global net present value mitigation costs (Panels b-e, discounted at $5 \%$ ) as a function of cumulative FF\&I emissions reductions in the $550 \mathrm{ppm}, 450 \mathrm{ppm}$ and FP scenarios (connected by dashed lines) with default technology assumptions. Carbon prices vary regionally for the FP scenario as indicated by vertical ranges. Consumption losses in IMACLIM set the upper end of the range as given in the text

\subsection{Energy system transformation pathways}

Emissions in the energy system can be mitigated in two ways: by reducing energy demand and by decarbonizing the energy mix. The mitigation pathways achieving the 450 and 
550 ppm $\mathrm{CO}_{2}$ e targets show a decarbonization of the energy system in the $21^{\text {st }}$ century at rates well beyond historical rates. Models reduce FF\&I emissions with a general strategy of decarbonizing electricity generation, a sector for which many non- or low-emissions technologies are available, and then substituting electric power and end-use efficiency for fossil fuel use in end-use sectors (Figs. 2, S3, 4; Krey et al. this issue). In most models, the use of solid fuels in industry and liquid fuels in transportation remains substantial.

Fossil fuel resources are not the limiting factor for GHG emissions. The decarbonization of the energy system leads to a strongly decreasing fossil fuel consumption compared to the baseline

a

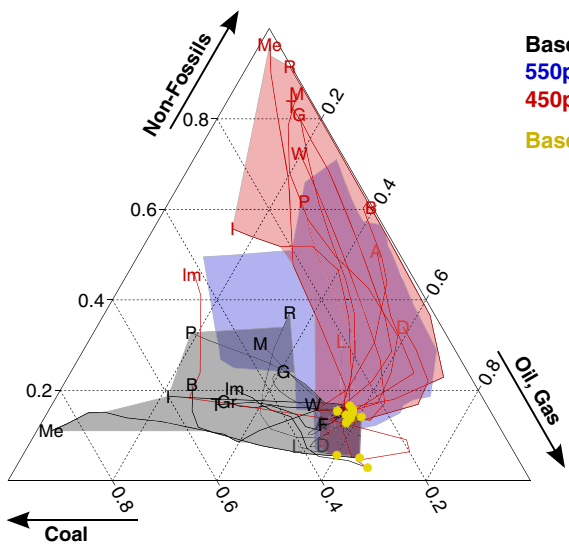

C Electricity Generation

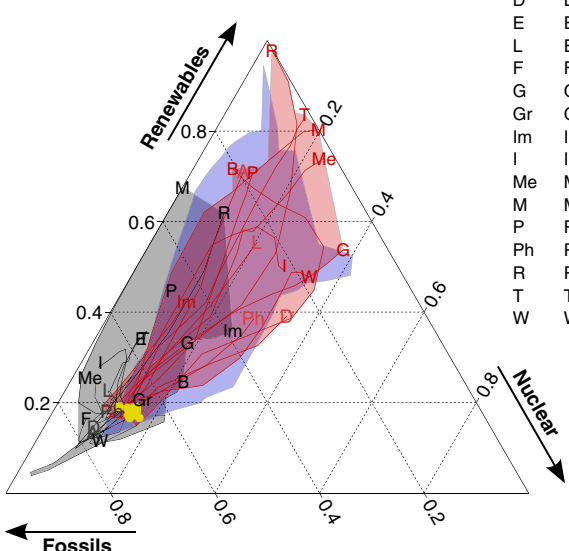

b Low-Carbon Primary Energy Supply

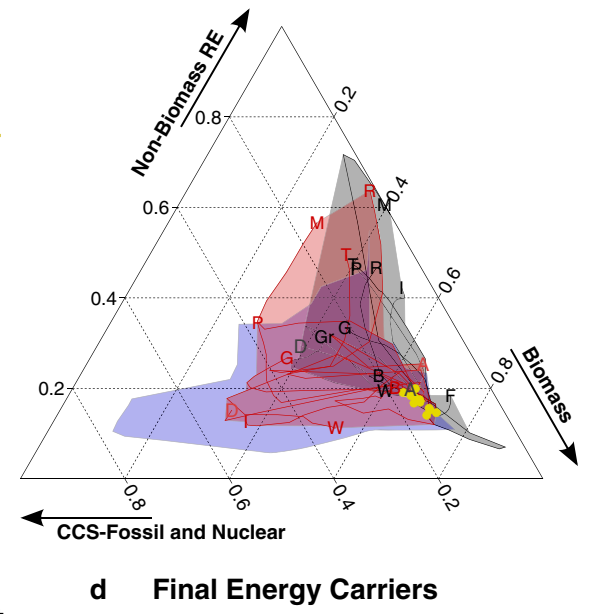
EC-IAM ENV-Linkages FARM GCAM GRAPE IMACLIM IMAGE MERGE MESSAGE POLES Phoenix REMIND TIAM-WORLD WITCH

RLD

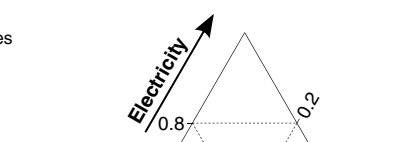

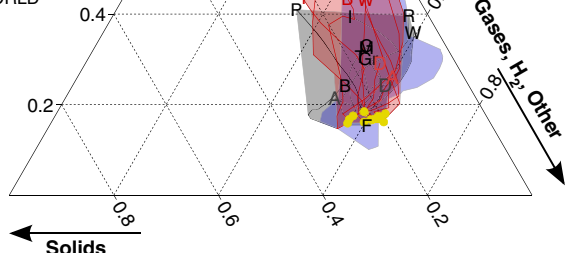

Fig. 4 Development of energy carrier shares in (a) primary energy supply, (b), low-carbon primary energy supply, (c) electricity generation, and (d) final energy in the baseline and climate policy cases (for default technology assumptions). Model markers show the shares in 2100 or - for AIM-Enduse, DNE21+, ENVLinkages and Phoenix - in 2050 (in italics). Primary energy shares for EC-IAM, MERGE and ENV-Linkages do not include traditional biomass. Corners constitute the extreme cases of $100 \%$ share of the respective energy carrier moving to lower shares in the direction of the opposite side $(0 \%)$. Dotted isolines (parallel to the opposite side) indicate shares of $20 \%, 40 \%, 60 \%$ and $80 \%$ 
development (McCollum et al. this issue). Climate policies could lead to a major reallocation of financial flows in fossil fuel markets between regions and near-term synergies for energy security.

The pace of the transformation of the energy system is accelerated significantly when moving from the 550 to the $450 \mathrm{ppm} \mathrm{CO}_{2}$ e target, with both low-carbon supply side options and energy efficiency being significantly upscaled. Energy intensity improvements are accelerated to 1.3$2.9 \%$ (Median: $2.3 \%$ ) per year for reaching $450 \mathrm{ppm} \mathrm{CO}_{2} \mathrm{e}$ compared to the 1970-2010 global rate of $1.3 \%$ per year (Sugiyama et al. this issue). In addition, the direct emissions from the enduse sectors are reduced or compensated by negative emissions to a much larger degree under the 450 ppm $\mathrm{CO}_{2} \mathrm{e}$ target. CCS and bioenergy, and in particular the combination of both (BECCS), play a crucial role in this (Rose et al. (a) this issue). BECCS notably affects the costeffective global emissions trajectory by accommodating prolonged use of fossil fuels without CCS. It should be noted that many models lack representation of alternative negative emissions technologies such as afforestation.

CCS is deployed at a substantial scale in almost all EMF27 mitigation scenarios with full technology availability (Figure S4; Koelbl et al. this issue). It can be combined with a variety of feedstocks and energy conversion technologies. While before 2050, coal, gas and biomass are used with CCS at comparable scale, biomass is becoming the most important CCS feedstock in the second half of the century because of the resulting net negative emissions. Rose et al. (this issue (a)) find modern bioenergy projected to grow 1$10 \%$ per annum through 2050, with bioenergy reaching 1-35\% of global primary energy by 2050 , and $10-50 \%$ by 2100 exhibiting a wide range across the models. A comparative analysis of the land use implications (Popp et al. this issue) found significant differences between three models with integrated land use components in EMF27 (GCAM, IMAGE, REMIND/MAgPIE). Under climate policy, bioenergy cropland represents $24-36 \%$ of total cropland by 2100 , but bioenergy feedstocks, land use emissions and carbon sinks vary notably across models. More research is needed to better understand the role of land use in climate stabilization.

In the climate policy scenarios, renewables contribute significantly to long-term electricity supply, while the contribution of renewables other than biomass to non-electric energy supply is limited. Deployment levels, in particular for wind and solar power, vary considerably across models due to differences in assumptions about costs and resource potentials, and the representation of integration challenges related to fluctuating supply from wind and solar power (Luderer et al. this issue). The majority of models project nuclear energy use for electricity generation to increase in the climate policy scenarios relative to the baseline, but deployment levels vary widely due to different assumptions about costs and uranium availability, and perspectives on nuclear risk factors (Kim et al. this issue). Models show different trade-offs between nuclear and renewable electricity, with some models projecting shares of comparable size (DNE21+, GCAM, EC-IAM, IMAGE, Phoenix, WITCH), and others foreseeing a dominant role of renewable electricity in the long run (AIM-Enduse, BET, MERGE, MESSAGE, POLES, REMIND, TIAMWorld; Fig. 3c).

\subsection{The impact of limiting technology availability}

The importance of individual mitigation technologies for reaching long-term climate targets can be studied by comparing scenarios with different technology availability. We use the increase in mitigation costs due to constraining technology availability as a measure of the value of the constrained technology cluster. Of course, specific values depend on the technology assumptions that were employed in the constrained 


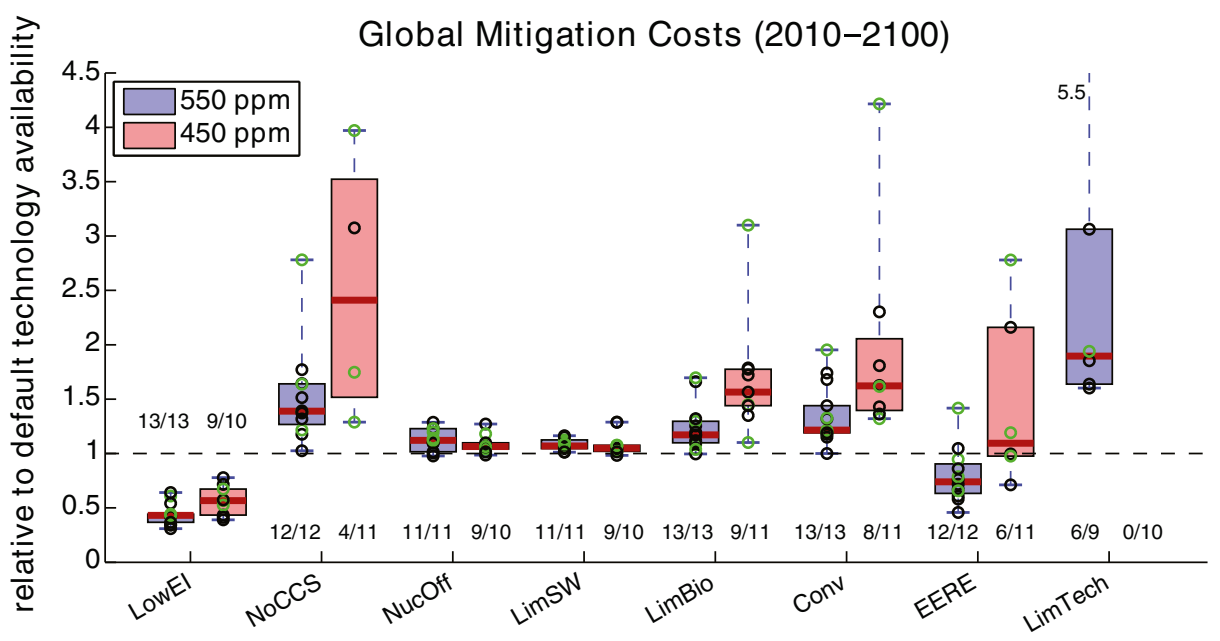

Fig. 5 Technology values measured in terms of mitigation costs (NPV discounted at $5 \%$ ) in the technology variant case (labeled on $\mathrm{x}$ ) relative to the FullTech case. The sample statistics is given below the boxplots (Feasible runs/Attempted runs). Different cost metrics are highlighted by black (consumption losses) and green (area under MAC) colouring of data points

vs full technology cases and will vary across models. Nonetheless, the broad picture of the importance of different technology clusters is captured by the results shown in Fig. 5.

In many models, transport and industry are the limiting sectors with regards to emissions reductions, with high-cost decarbonization options in these sectors often driving mitigation costs. Consequently, limitations on mitigation options relevant for non-electric energy use, primarily bioenergy and CCS, have a strong impact on mitigation costs (Fig. 5, Krey et al. this issue). Their value is further increased by the fact that their combination (BECCS) can be used to produce negative emissions. By contrast, limited availability and performance of options constrained to the electricity sector such as nuclear, solar and wind power showed a smaller impact on mitigation costs due to a relatively large substitutability among these options. The assumption of approx. $50 \%$ larger energy intensity improvement rates lead to a significant reduction in mitigation costs. This result may not, however, include the full costs of improving energy efficiency, as most models have a very limited accounting of demand side investments and costs.

Reliance on the full portfolio of mitigation technologies increases when moving from the 550 to the 450 ppm $\mathrm{CO}_{2}$ e target. Models could identify transformation pathways under the $550 \mathrm{ppm} \mathrm{CO}_{2}$ e target for all limited mitigation technology portfolios considered in this study - albeit at different costs. By contrast, only four models could achieve the $450 \mathrm{ppm}$ $\mathrm{CO}_{2} \mathrm{e}$ target without CCS. Variation of mitigation costs with technology availability is much stronger under a stringent $450 \mathrm{ppm} \mathrm{CO}_{2} \mathrm{e}$ target compared to the $550 \mathrm{ppm} \mathrm{CO}_{2} \mathrm{e}$ target (Fig. 5).

Some of the technology variations, most notably if CCS is not available or if bioenergy is limited, lead to significant changes in the emissions profiles compared to the full-technology availability counterparts (Krey et al. this issue; Rose et al. (b) this issue). The reason for this is related to the associated constraint on negative emissions that can no longer be deployed (to the original extent) in the long run to compensate for more emissions in the short term. 
The study also investigated a counterfactual scenario with limitations on all mitigation technology clusters, defined as the combination of the individual technology constraints considered in the study (LimTech). Mitigation costs for achieving a $550 \mathrm{ppm} \mathrm{CO}_{2} \mathrm{e}$ target increased significantly compared to the situation in which the availability of only a subset of technology clusters was limited. No model could find a solution to achieve the $450 \mathrm{ppm} \mathrm{CO}_{2} \mathrm{e}$ target under these conditions. This highlights the fact that technology is a central component of meeting the climate stabilization challenge.

\section{Discussion and conclusions}

The EMF27 study has explored global technology strategies for climate mitigation under various assumptions on long-term global climate policies and technology availability (Table 1). The study included 18 energy-economy and integrated assessment models from Europe, Asia and North America. Model comparison studies like EMF27 can be effectively used to check the robustness of findings from individual models. While mitigation pathways have been investigated in previous model inter-comparison projects, and many findings of EMF27 confirm earlier findings, EMF27 provides the most comprehensive assessment to date with updated results on the role of energy end use sectors, energy supply technologies, energy efficiency, negative emissions, land use based mitigation, the scope of fragmented action and mitigation costs. We summarize several major findings below.

Emissions: Extrapolating current levels of fragmented policy action or increasing energy intensity improvement rates by $50 \%$ fall short of emissions reductions that would be required for reaching the 450 and $550 \mathrm{ppm} \mathrm{CO}_{2} \mathrm{e}$ targets. Models exhibit considerable uncertainty about the emissions implications of long-term climate targets and project different allocations of the mitigation effort across sectors with particular uncertainty about the use of land use based mitigation options. Thus, a climate target can be consistent with a range of caps on cumulative future fossil fuel emissions.

Energy transformation and technology value: Mitigation pathways show a massive transformation of the energy system. Robust characteristics of this transformation are increased energy intensity improvements and the electrification of energy end use coupled with a fast decarbonization of the electricity sector. Results indicate that non-electric energy end use is hardest to decarbonize. Technology is a key element for reaching climate targets. Versatile technologies such as CCS and bioenergy have largest value, part of it due to their combined ability to produce negative emissions. The availability of a negative emissions technology seems to be a key element for meeting the climate targets due to the ability to compensate fossil fuel emissions across sectors and time. A multitude of mitigation options in the electricity sector limit dependence on individual mitigation technologies. Rapid energy intensity improvements reduce the mitigation challenge significantly.

The $450 \mathrm{ppm} \mathrm{CO}_{2} \mathrm{e}$ target requires a stronger decarbonization of non-electric energy use, and a larger deployment of negative emissions compared to the $550 \mathrm{ppm} \mathrm{CO}_{2} \mathrm{e}$ target. As a result, the achievability and the costs of the $450 \mathrm{ppm} \mathrm{CO}_{2} \mathrm{e}$ target are more sensitive to variations in technology availability.

Economic implications: Mitigation costs increase by a factor of 1.5 to 2.5 in the large majority of models when moving from $550 \mathrm{ppm}$ to $450 \mathrm{ppm} \mathrm{CO}_{2} \mathrm{e}$, but remain below $3.5 \%$ of the baseline economy (NPV for 2010-2100) for all but one model if technology availability is not constrained. The costs are moderated by the availability of BECCS in most models, particularly for the $450 \mathrm{ppm} \mathrm{CO}_{2} \mathrm{e}$ target. Cost numbers depend on the idealized policy 
assumption of universal carbon pricing and largely efficient markets. Regional fragmentation leads to higher mitigation costs for achieving the same level of emissions reduction.

Near term implications: Finally, we note that the differences in emissions and energy technology deployments between 450 and $550 \mathrm{ppm}$ mitigation pathways are limited until 2030, even though they are significant in the long term. This is facilitated by the fact that the $450 \mathrm{ppm} \mathrm{CO} 2$ e target allows for overshooting the target prior to 2100, which can be exploited in particular if negative emissions are available in the long run to compensate for relatively higher near-term emissions. The implications of alternative near-term emissions targets for long-term climate goals are investigated by a concurrent study (Riahi et al., 2013).

Several caveats of the study need to be highlighted. For reaching the long-term climate targets, the study assumes universal emissions pricing starting almost immediately. In the real world, global cooperative action is unlikely to be implemented before 2020, and prospects thereafter are uncertain. In addition, models do not account for the institutional challenges that implementing a price on carbon may bring on the national to regional scale. All of these factors can substantially increase the mitigation challenge, including the costs of mitigation. The study also focused on the direct impacts of mitigation, not including benefits from avoided climate change, co-benefits to other policy objectives such as air pollution, nor adverse side effects, e.g. on food security. These dimensions need to be taken into account when putting the results of this study into a policy context.

We conclude that ambitious climate policy objectives imply a large-scale transformation of the energy and land system. The higher the ambition, the more important the availability of key technologies and an efficient global climate policy regime will be.

Acknowledgments Jae Edmonds and Leon Clarke are grateful for research support provided by the Integrated Assessment Research Program in the Office of Science of the U.S. Department of Energy under Contract No. DE-AC05-76RL01830. Results reported for the GCAM model used Evergreen computing resources at the Pacific Northwest National Laboratory's Joint Global Change Research Institute at the University of Maryland in College Park, which is supported by the Integrated Assessment Research Program in the Office of Science of the U.S. Department of Energy. The views and opinions expressed in this paper are those of the authors alone.

The contribution of Elmar Kriegler, Volker Krey, Gunnar Luderer, Keywan Riahi, Massimo Tavoni and Detlev van Vuuren to this research was supported by funding from the European Commission's Seventh Framework Programme under the LIMITS project (grant agreement no. 282846).

\section{References}

Azar C et al (2010) The feasibility of low $\mathrm{CO}_{2}$ concentration targets and the role of bio-energy with carbon capture and storage (BECCS). Clim Chang 100:195-202

Bibas R, Méjean A (this issue) Potential and limitations of bioenergy options for low carbon transitions. Clim Chang, submitted

Blanford GJ, Kriegler E, Tavoni M (this issue) Harmonization vs. Fragmentation: Overview of climate policy scenarios in EMF27. Clim Chang, submitted

Calvin K et al (2012) The role of Asia in mitigating climate change: results from the Asia modeling exercise. Energy Econ 34(3):S251-S260

Clarke L et al (2008) $\mathrm{CO}_{2}$ emissions mitigation and technological advance: an updated analysis of advanced technology scenarios. PNNL Report Pacific Northwest National Laboratory, Richmond

Clarke L, Edmonds J, Krey V, Richels R, Rose S, Tavoni M (2009) International climate policy architectures: overview of the EMF 22 international scenarios. Energy Econ 31:S64-S81

Edenhofer $\mathrm{O}$ et al (2010) The economics of low stabilization: Model comparison of mitigation strategies and costs. Energy J 31:11-48 
European Commission, Joint Research Centre (JRC)/PBL Netherlands Environmental Assessment Agency (2011) Emission Database for Global Atmospheric Research (EDGAR), release version 4.2. http://edgar.jrc.ec. europe.eu

Kim SH, Wada K, Kurosawa A, Roberts M (this issue) Nuclear energy response in the EMF27 study. Clim Chang, submitted

Koelbl BS, van den Broek MA, Faaij APC, van Vuuren DP (this issue) Uncertainty in Carbon Capture and Storage (CCS) deployment projections: a cross-model comparison exercise. Clim Chang, submitted

Krey V, Clarke L (2011) Role of renewable energy in climate mitigation: a synthesis of recent scenarios. Clim Pol 11:1131-1158

Krey V, Luderer L, Clarke L, Kriegler E (this issue) Getting from here to there: energy technology transformation pathways in the EMF27 scenarios. Clim Chang, submitted

Luderer G, Bosetti V, Jakob M, Leimbach M, Steckel JC, Waisman H, Edenhofer O (2012) The economics of decarbonizing the energy system-results and insights from the RECIPE model intercomparison. Clim Chang 114:9-37

Luderer $\mathrm{G}$ et al. (this issue) The role of renewable energy in climate mitigation: results from the EMF27 scenarios. Clim Chang submitted

McCollum DL, Krey V, Riahi K (2011) An integrated approach to energy sustainability. Nat Clim Chang 1(9):428-429

McCollum D, Bauer N, Calvin K, Kitous A, Riahi K (this issue) Fossil resource and energy security dynamics in conventional and carbon-constrained worlds. Clim Chang, submitted

Meinshausen $\mathrm{M}$ et al (2009) Greenhouse-gas emission targets for limiting global warming to $2^{\circ} \mathrm{C}$. Nature 458:1158-1162

Nakicenovic N, Nordhaus W (2011) Editors' introduction: the economics of technologies to combat global warming. Energy Econ 33(4):565-571

Popp A et al. (this issue) Land-use transition for bioenergy and climate stabilization: model comparison of drivers, impacts and interactions with other land use based mitigation options. Clim Chang, submitted

Riahi K et al (2012) Chapter 17 - Energy pathways for sustainable development. Global energy assessment toward a sustainable future. IIASA and Cambridge University Press, Cambridge, pp 1203-1306

Riahi K et al (2013) Locked into Copenhagen pledges - Implications of short-term emission targets for the cost and feasibility of long-term climate goals. Technological Forecasting and Social Change. doi:10.1016/ j.techfore.2013.09.016

Rose SK, Kriegler E, Bibas R, Calvin K, Popp A, van Vuuren DP, Weyant J (this issue, (a)), Bioenergy in energy transformation and climate management. Clim Chang, submitted

Rose SK, Richels R, Smith S, Riahi K, Strefler J, van Vuuren D (this issue, (b)) Non-Kyoto radiative forcing in long-run greenhouse gas emissions and climate change scenarios. Clim Chang, submitted

Sugiyama M, Akashi O, Wada K, Kanudia A, Li J, Weyant J (this issue) Role of energy efficiency in climate change mitigation policy for India: Assessment of co-benefits and opportunities within an integrated assessment modeling framework. Clim Chang, submitted

Tavoni M, Socolow R (2013) Modeling meets science and technology: an introduction to a special issue on negative emissions. Clim Chang 118(1):1-14

Tavoni M, Tol R (2010) Counting only the hits? The risk of underestimating the costs of stringent climate policy. Clim Chang 100:769-778

Weyant JP, de la Chesnaye FC, Blanford GJ (2006) Overview of EMF-21: Multigas Mitigation and Climate Policy. Energy J, Special Issue

Weyant JP (2004) EMF 19: alternative technology strategies for climate change policy. Energy Econ 26(4):501-575 